\title{
A Cost-Effective Method for Rapid Manufacturing a Precision Mold With Microstructures Using Hybrid Manufacturing Technologies
}

Chil-Chyuan Kuo ( $\nabla$ jacksonk@mail.mcut.edu.tw)

Ming Chi University of Technology https://orcid.org/0000-0003-0519-4126

Bo-Han Lin

Ming Chi University of Technology

Zheng-Ting Luo

Ming Chi University of Technology

\section{Research Article}

Keywords: Additive manufacturing, Rapid tooling, Computer numerical control machining,

Microstructures, Injection molding, Precision mold

Posted Date: February 12th, 2021

DOI: https://doi.org/10.21203/rs.3.rs-173996/v1

License: (a) (1) This work is licensed under a Creative Commons Attribution 4.0 International License.

Read Full License 


\section{Abstract}

Injection molding is a cost-effective to manufacture molded products by injection molding machine. A precision part with microstructures can be fabricated effectively through a precision mold. In this study, a cost-effective method for rapid manufacturing a precision component and a precision injection mold with microstructures by integrating additive manufacturing, rapid tooling, and computer numerical control milling. It was found that of the dimensional accuracy of a precision component in the length, width, and height can be controlled at approximately $30 \mu \mathrm{m}$. Injection molding was performed using an injection mold with microstructures with a microstructure of $950 \mu \mathrm{m}$ and the dimensional accuracy of a molded part in the length, width, and microstructure can be controlled at approximately $60 \mu \mathrm{m}, 50 \mu \mathrm{m}$, and $10 \mu \mathrm{m}$, respectively. The remarkable findings of this study can be used for the fabrication of molds or dies efficiently and economically for trial production in the mold industry since the quality of the precision component and the precision mold can meet the standards of the general industry.

\section{Introduction}

In order to maintain company competitiveness, reducing time to the market was considered as one of the important factors. To solve this problem, additive manufacturing (AM) [1] and rapid tooling (RT) technologies were proposed to reduce the production time and production cost. AM can produce prototype with complex geometries. Injection mold can be manufactured in a short time and at low cost by RT because RT can shorten the time to the market compared to conventional machining approaches [2-7]. It is widely known that computer numerical control (CNC) machining is the most effective method to manufacture components or molds with excellent surface quality, good dimensional accuracy, and microstructures [8]. Leal et al. [9] used AM to fabricate the stamping tools for the automotive industry. The mold surface quality is very important for a precision mold. The surface quality of the molds fabricated by AM can be improved by CNC machining [10], mathematic model [11], hot cutter machining [12], chemical finishing [13], or build orientation optimization [14]. In general, the injection mold can be fabricated by metal AM technologies such as direct metal laser sintering (DMLS) [15], electron beam melting (EBM) [16], selective laser melting (SLM) [17], selective laser sintering (SLS) [18], diffusion bonding (DB) [19], or direct metal deposition (DMD) [20].The advantage of the injection mold fabricated by metal AM technology is its excellent mechanical properties. Single trace deposition of Ti-6Al-4V wire over homologous substrate using DMD was investigated [21]. However, the surface quality of the injection mold fabricated by metal AM technology is not acceptable. In order to solve this drawback, hybrid manufacturing technology was proposed. Basinger et al. [22] developed a modular computer-aided process planning system for additive-subtractive hybrid manufacturing of pockets, holes, and flat surfaces. The injection mold can also be fabricated directly by AM using polymer materials such as acrylonitrile butadiene styrene [23-25]. However, the injection mold with microstructures can not be fabricated directly.

According to the literature reviews discussed above, it can be found that developing a low-cost method to rapid manufacture a precision mold with microstructures is an important research issue. In this study, a 
simple approach to rapid manufacture a precision injection mold with microstructures was proposed by integrating $\mathrm{AM}, \mathrm{RT}$, and $\mathrm{CNC}$ milling.

\section{Experimental Details}

The test part, precision component, molds, and research object were designed with the Pro/ENGINEER computer-aided design (CAD) software. The CAD models were exported as stereolithograpgy files to AM manufacturing system. The CAD models were then horizontally sliced into a set of thin layers using the CURA software (Ultimaker Inc.) for fabricating three-dimensional (3D) physical models. The polylactic acid (PLA) filament with a diameter of $1.5 \mathrm{~mm}$ was used as modeling materials to fabricate 3D physical models. The liquid silicone rubber (KE-1310ST, Shin Etsu Inc.) and hardener (CAT-1310, Shin Etsu Inc.) were used to make silicone rubber molds. The silicone rubber and hardener were mixed in a weight ratio of 10:1. A vacuum machine (F-600, Feiling, Inc.) was used to extract the air-bubbles resulting from the mixing process under vacuum conditions. The wax (K512, President Inc.) was selected as a molding material in the injection molding. Injection molding was carried out using a low-pressure wax injection molding machine (0660, W\&W Inc.). The process parameters for injection molding are injection pressure of $0.7 \mathrm{kgf} / \mathrm{cm}^{2}$, degassing time of $7 \mathrm{~s}$, injection temperature of $85^{\circ} \mathrm{C}$, and injection time of $5 \mathrm{~s}$. The dimensional changes in the process were measured using a vision measuring system (Quick Vision APEX 404 Pro, Mitutoyo). The recycled aluminum (Al)-filled epoxy resins (TE-365, Jasdi Chemicals Inc.) were then mixed with new epoxy resins (174 AB, Jasdi Chemicals Inc.) as a mixture to fabricate injection molds because this material is suitable for short production runs. The suspension ratio of the specimen was analyzed to determine the optimal mixing ratios of recycled powders and new epoxy resins using an optical microscopy. The fabricated rapid injection mold was then cured using a convection oven (DH400, Deng Yag) for achieving the required mechanical properties. A ball end mills with a radius of $0.5 \mathrm{~mm}$ was used to machine microstructures. A ball end mills with a radius of $1 \mathrm{~mm}$ was used for plane and surface machining. An end mill with a diameter of $6 \mathrm{~mm}$ was used for plane machining. A ball end mill with a diameter of $6 \mathrm{~mm}$ and a $0.5 \mathrm{~mm}$ corner radius was used for surface tangent plane machining. Figure 1 shows the steps of a cost-effective method for rapid manufacturing a precision part with microstructures using hybrid manufacturing technologies. Figure 2 shows the steps of a cost-effective method for rapid manufacturing a precision mold for injection molding. A product with microstructures was designed firstly. The upper mold and the lower mold were then designed according to the product. A precision mold for injection molding can be fabricated using hybrid manufacturing technologies.

\section{Results And Discussion}

In order to understand the limits of the microstructure in the physical model fabricated by AM, a physical model with nine different holes was fabricated. Figure 3 shows the different holes in the physical model fabricated by AM. It was found that the fine feature with a diameter less than $1 \mathrm{~mm}$ cannot be printed directly. Therefore, a fine feature in the component or mold with a dimension less than $1 \mathrm{~mm}$ must be machined by computer numerical control machining. Figure 4 shows the surface quality of a test part 
before and after CNC milling. Two important phenomena were observed. One is the surface quality of the physical model can be improved significantly with amount of finish of $0.4 \mathrm{~mm}$ in the vertical direction. The other is no more amount of finish in the horizontal direction because the physical model has a dimensional error of about $0.2-0.3 \mathrm{~mm}$ in one side of the horizontal direction which can be mainly attributed to the drive motor positioning error. In order to maintain both dimensional accuracy and surface quality of the part after CNC milling, the height of the CAD model needs to add $0.4 \mathrm{~mm}$ as the amount of finish. Figure 5 shows the process flows for maintaining both dimensional accuracy and surface quality of the part using CNC machining. Figure 6 shows the result of a test part with microstructures. This result shows the part with excellent surface quality, good dimensional accuracy as well as a microstructure of $950 \mu \mathrm{m}$ can be fabricated swiftly and economically thought AM, RT, and computer numerical control milling technologies.

The length, width, and height of a precision component are $118 \mathrm{~mm}, 60 \mathrm{~mm}$ and $34.5 \mathrm{~mm}$, respectively. According to the experience of the test part, the length, width, and height are then changed to $118 \mathrm{~mm}, 60$ $\mathrm{mm}$, and $34.9 \mathrm{~mm}$, respectively. The shrinkage of the silicone rubber and Al-filled epoxy resins are almost negligible because the shrinkage of the silicone rubber and Al-filled epoxy resins were approximately $0.5 \%$ and $0.8 \%$, respectively. Figure 7 shows the variations in dimension of the precision component manufacturing process for length, width, and height. The average length, width, and height of a precision component after NC machining were $117.97 \mathrm{~mm}, 60.03 \mathrm{~mm}$, and $34.53 \mathrm{~mm}$, respectively. This result means that the dimensional accuracy of a precision component in the length, width, and height approximately $30 \mu \mathrm{m}$ can be obtained. In is noteworthy that the quality of this precision component can meet the standards of the general industry because the dimensional accuracy of the precision component in the industry is about $50 \mu \mathrm{m}$. Figure 8 shows a precision component before and after CNC milling. As can be seen, this precision component has excellent surface quality and good dimensional accuracy.

The length, width, and microstructures of the injection molded product designed are $57 \mathrm{~mm}, 36 \mathrm{~mm}$, and $0.95 \mathrm{~mm}$, respectively. The average length, width, and microstructure of the injection molded product are $56.94 \mathrm{~mm}, 35.95 \mathrm{~mm}$, and $0.94 \mathrm{~mm}$, respectively. Figure 9 shows the variations in dimension of the precision mold manufacturing process for length, width, and microstructures. The shrinkage of the wax is about $1.5 \%$. The dimensional accuracy of a molded part in the length, width, and microstructure approximately $60 \mu \mathrm{m}, 50 \mu \mathrm{m}$, and $10 \mu \mathrm{m}$ can be obtained. This result means a precision mold for injection molding can be fabricated in a short time and at low cost. Figure 10 shows a precision injection mold with microstructure. In order to evaluate the effectiveness of the fabricated precision mold, lowpressure wax injection molding was carried out. Figure 11 shows a wax pattern with microstructures fabricated by a precision injection mold through injection molding. This result shows the fabricated precision mold has excellent mechanical properties[26]for low-volume production of precision wax patterns to manufacture a variety of metallic components using investment casting technology [27-29]. Figure 12 shows a precision injection mold fabricated by only AM technology and hybrid manufacturing technology. This result clearly revealed that it is impossible to fabricate a precision injection mold with microstructures only by the use of AM. A distinct advantage of a precision injection mold fabricated by 
the proposed method is no residual thermal stress inside the mold compared to that fabricated by DMLS [30].

Generally, the production costs of a precision injection mold with microstructures fabricated by DMLS, EBM, SLM [31, 32], SLS [33], DB [34], DMD, or laser metal deposition (LMD) is expensive. However, the costs of materials used in this study, such as PLA filaments, silicone rubber, and Al-filled epoxy resins were inexpressive. The 3D physical models were fabricated with PLA filament using fused deposition modeling [35]. The intermediary silicone rubber mold was fabricated by liquid silicone rubber. The component and injection mold were fabricated by Al-filled epoxy resins. The surface quality of the component and injection mold was improved without losing the dimensional accuracy by CNC milling. The microstructures $[36,37]$ in the component or injection mold were also machined by CNC milling. Therefore, a precision mold with a microstructure can be fabricated swiftly and economically. According to the results discussed above, it can be concluded that a simple and cost-effective method to manufacture a precision mold with microstructures was demonstrated by integrating AM, RT, and CNC milling [38]. The findings of this work are very useful and provide the greatest application potential in both the precision machinery and investment casting industries since this technology can be employed to fabricate a precision mold for most general engineering purposes in the research and development stage. In this study, the material of the final precision injection mold is Al-filled epoxy resins. Ordinarily, the main disadvantage of the precision injection mold is that the mold service life was limited by the characteristics of injection mold materials. Therefore, some reinforcing additives, such as wollastonite, molybdenum disulfide [39-41], silica sand, glass sphere, zirconia [42-44], silicon nitride [45-47], or silica sand were recommended for adding to the injection mold. In this study, the injection mold was employed in wax injection molding for manufacturing precision wax patterns. Note that the proposed method can also be employed in plastic injection molds [48-50,], blow molding dies [51], metal injection molding molds [52], powder metallurgy molds [53], die casting dies [54], hot extrusion dies [55, 56], injectioncompression molding molds [57], rotational molding dies, thermoforming molds, transfer molding dies, or hot stamping dies [58]. Finally, it is worth noting that two further studies are required for enhancing the surface quality of a precision mold machined and dimensional accuracy of a precision mold machined. One is accurate tool condition monitoring [59] is required during CNC milling. The other is that the surface quality monitoring [60] of a precision mold is also required during CNC milling. These issues are currently being investigated and the results will be presented in a later study.

\section{Conclusions}

The aim of this study is to develop a cost-effective approach for rapid manufacturing a precision product with microstructures using a precision mold fabricated by integrating $A M, R T$, and CNC milling. The proposed method is very effective to fabricate a precision mold, especially for the molded part with complex geometries. Based on the results discussed in this study, the following conclusions can be drawn: 
1. The findings of this study are very practical and provide the greatest application potential in the both investment casting and precision machinery industries.

2. A precision mold with a microstructure of $950 \mu \mathrm{m}$ can be fabricated in a short time and at low cost.

3. The quality of the fabricated precision mold can meet the standards of the general industry and has excellent mechanical properties for injection molding.

4. The dimensional accuracy of a molded part in the length, width, and microstructure approximately $60 \mu \mathrm{m}, 50 \mu \mathrm{m}$, and $10 \mu \mathrm{m}$ can be obtained.

\section{Declarations}

\section{Ethical Approval}

YES .The manuscript should not be submitted to more than one journal for simultaneous consideration.

YES The submitted work should be original and should not have been published elsewhere in any form or language (partially or in full), unless the new work concerns an expansion of previous work. (Please provide transparency on the re-use of material to avoid the concerns about text-recycling ('selfplagiarism').

YES A single study should not be split up into several parts to increase the quantity of submissions and submitted to various journals or to one journal over time (i.e. 'salami-slicing/publishing').

YES Concurrent or secondary publication is sometimes justifiable, provided certain conditions are met. Examples include: translations or a manuscript that is intended for a different group of readers.

YES Results should be presented clearly, honestly, and without fabrication, falsification or inappropriate data manipulation (including image based manipulation). Authors should adhere to discipline-specific rules for acquiring, selecting and processing data.YES No data, text, or theories by others are presented as if they were the author's own ('plagiarism'). Proper acknowledgements to other works must be given (this includes material that is closely copied (near verbatim), summarized and/or paraphrased), quotation marks (to indicate words taken from another source) are used for verbatim copying of material, and permissions secured for material that is copyrighted.

\section{Consent to Participate}

I understand that all information I provide for this study will be treated confidentially.

\section{Consent to Publish}

All authors agreed to the consent to publish. 
Author's signature:

Date:

\section{Chil-Chyuan}

\section{Kuo/ Chil-Chyuan kuo}

\section{Authors Contributions}

All authors have read and agreed to the consent to the published version of the manuscript.

Arthur 1: Chil-Chyuan Kuo---Wrote the paper/ Conceived and designed the analysis/ Performed the analysis/Conceptualization

Arthur 2/ 3: Bo-Han Lin, Zheng-Ting Luo --Simulation/Experiment/Collected the data/Contributed data or analysis tools

\section{Funding}

This study received financial support by the Ministry of Science and Technology of Taiwan under contract nos. MOST 109-2637-E-131-004, MOST 107-2221-E-131-018, MOST 106-2221-E-131-010, MOST 106-2221-E-131-011, and MOST 105-2221-E-131-012.

\section{Conflicts of Interest / Competing Interests}

The authors declare that they have no known competing financial interests or personal relationships that could have appeared to influence the work reported in this paper.

\section{Availability of data and materials}

Data openly available in a public repository that issues datasets with DOls

\section{References}

1. Thomas," Costs, benefits, and adoption of additive manufacturing: a supply chain perspective," The International Journal of Advanced Manufacturing Technology, Volume 85, Issue 5-8, 2016, Pages 1857-1876.

2. Armillotta, R. Baraggi, S. Fasoli," SLM tooling for die casting with conformal cooling channels," he International Journal of Advanced Manufacturing Technology, Volume 71, Issue 1-4, 2014, Pages 573-583. 
3. Maji, P.K., Banerjee, P.S. \& Sinha, A. Application of rapid prototyping and rapid tooling for development of patient-specific craniofacial implant: an investigative study. Int J Adv Manuf Technol 36, 510-515 (2008).

4. Kalami, H., Urbanic, R.J. Design and fabrication of a low-volume, high-temperature injection mould leveraging a 'rapid tooling' approach. Int J Adv Manuf Technol 105, 3797-3813 (2019)

5. C. Kuo, S. Y. Lyu, "A cost-effective approach using recycled materials to fabricate micro-hot embossing die for microfabrication," The International Journal of Advanced Manufacturing Technology, Volume 94, Issue 9-12, 2018, Pages 4365-4371.

6. Kuo, CC., You, ZY., Chang, SJ. et al. Development of green conformal cooling channels for rapid tooling. Int J Adv Manuf Technol 111, 109-125 (2020).

7. Kuo, CC., Chen, WJ. Development and application of intelligent monitoring system for rapid tooling applied in low-pressure injection molding. Int J Adv Manuf Technol 111, 3453-3467 (2020).

8. O. dos Santos, G. F. Batalha, E. C. Bordinassi, G. F. Miori," Numerical and experimental modeling of thermal errors in a five-axis CNC machining center," The International Journal of Advanced Manufacturing Technology, Volume 96, Issue 5-8, 2018, Pages 2619-2642.

9. Leal,F. M. Barreiros,L. Alves,F. Romeiro, J. C. Vasco, M. Santos, C. Marto," Additive manufacturing tooling for the automotive industry," The International Journal of Advanced Manufacturing Technology, Volume 92, Issue 5-8, 2017, Pages 1671-1676.

10. Boschetto, L. Bottini, F. Veniali," Finishing of Fused Deposition Modeling parts by CNC machining," Robotics and Computer-Integrated Manufacturing, Volume 41, 2016, Pages 92-101.

11. Noriega,D. Blanco, B. J. Alvarez, A. Garcia," Dimensional accuracy improvement of FDM square cross-section parts using artificial neural networks and an optimization algorithm," The International Journal of Advanced Manufacturing Technology, Volume 69, Issue 9-12, 2013, Pages 2301-2313.

12. M. Pandey, N. V. Reddy, S. G. Dhande," Improvement of surface finish by staircase machining in fused deposition modeling," Journal of Materials Processing Technology, Volume 132, Issues 1-3, 2003, Pages 323-331.

13. Percoco, F. Lavecchia, L. L. M. Galantucci ," Compressive Properties of FDM Rapid Prototypes Treated With A Low Cost Chemical Finishing ," Research Journal of Applied Sciences, Engineering and Technology, Volume 4, Issue 19, 2012, Pages 3838-3842.

14. Jaiswal, J. Patel, R. Rai," Build orientation optimization for additive manufacturing of functionally graded material objects," The International Journal of Advanced Manufacturing Technology, Volume 96, Issue 1-4, 2018, Pages 223-235.

15. AlMangour and J. M. Yang," Understanding the deformation behavior of 17-4 precipitate hardenable stainless steel produced by direct metal laser sintering using micropillar compression and TEM," he International Journal of Advanced Manufacturing Technology, , Volume 90, Issue 1-4, 2017, Pages $119-126$.

16. Scharowsky, A. Bauereib, C. Korner," Influence of the hatching strategy on consolidation during selective electron beam melting of Ti-6Al-4V," The International Journal of Advanced Manufacturing 
Technology, Volume 92, Issue 5-8, 2017, Pages 2809-2818.

17. Liu, Y. Yang, D. Wang, " A study on the residual stress during selective laser melting (SLM) of metallic powder," The International Journal of Advanced Manufacturing Technology, Volume 87, Issue 1-4, 2016, Pages 647-656.

18. L. Leite, G. V. Salmoria, R. A. Paggi, C. H. Ahrens, A. S. Pouzada, “Microstructural characterization and mechanical properties of functionally graded PA12/HDPE parts by selective laser sintering," The International Journal of Advanced Manufacturing Technology, Volume 59, Issue 5-8, 2012, Pages 583-591.

19. Lin, H. Luo, W. Huang, X. Zhang, G. Yao," Diffusion bonding in fabrication of aluminum foam sandwich panels," Journal of Materials Processing Technology, Volume 230, 2016, Pages 35-41.

20. I. Gorunov and A. Kh. Gilmutdinov," Study of the effect of heat treatment on the structure and properties of the specimens obtained by the method of direct metal deposition," The International Journal of Advanced Manufacturing Technology, Volume 86, Issue 9-12, 2016,Pages 2567-2574.

21. Caiazzo," Additive manufacturing by means of laser-aided directed metal deposition of titanium wire," The International Journal of Advanced Manufacturing Technology, Volume 96, Issue 5-8, 2018, Pages 2699-2707.

22. L. Basinger ,C. B. Keough, C. E. Webster, R. A. Wysk, T.M. Martin, O. L. Harrysson,” Development of a modular computer-aided process planning (CAPP) system for additive-subtractive hybrid manufacturing of pockets, holes, and flat surfaces," The International Journal of Advanced Manufacturing Technology, Volume 96, Issue 5-8, 2018, Pages 2407-2420.

23. Li, J. Zhao, J. Jiang, H. Jiang, W. Wu, M. Tang," Ultrasonic strengthening improves tensile mechanical performance of fused deposition modeling 3D printing," The International Journal of Advanced Manufacturing Technology, Volume 96, Issue 5-8, 2018, Pages 2747-2755.

24. C. Kuo, C. M. Chen, S. X. Chang, “Polishing mechanism for ABS parts fabricated by additive manufacturing," The International Journal of Advanced Manufacturing Technology, Volume 91, Issue 5-8, 2017, Pages 1473-1479.

25. C. Kuo, C. W. Wang, Y. F. Lee, Y. L. Liu, Q.Y. Qiu, "A surface quality improvement apparatus for ABS parts fabricated by additive manufacturing," The International Journal of Advanced Manufacturing Technology, Volume 89, Issue 1, 2017, Pages 635-642.

26. Zhong, J. Chen, A. Gasser, S. Sui, J. H. Schleifenbaum," Microstructures, tensile properties, and fracture mechanisms of Inconel 718 formed by HDR-LMD with PREP and GA powders," The International Journal of Advanced Manufacturing Technology, Volume 96, Issue 5-8, 2018, Pages 2031-2041.

27. Wang, A. Dong, G. Zhu, D. Shu, F. Li," The propagation and accumulation of dimensional shrinkage for ring-to-ring structure in investment casting," The International Journal of Advanced Manufacturing Technology, Volume 96, Issue 1-4, 2018, Pages 623-629.

28. H. Huang, C. J. Lin, "Computer-aided modeling and experimental verification of optimal gating system design for investment casting of precision rotor," The International Journal of Advanced 
Manufacturing Technology, Volume 79, Issue 5, 2015, Pages 997-1006.

29. Li, J. Chen, K. Chandrashekhara , M. Xu, S. N. Lekakh, V. L. Richards," Characterization and modeling of anisotropic SL pattern during investment casting process," The International Journal of Advanced Manufacturing Technology, Volume 80, Issue 9, 2015, Pages 1933-1943.

30. Yan, H., Shen, L., Wang, X. et al. Stress and deformation evaluation of the subarea scanning effect in direct laser-deposited Ti-6Al-4V. Int J Adv Manuf Technol 97, 915-926 (2018).

31. Ye, G. S. Hong, Y. Zhang, K. Zhu, J. Y. H. Fuh," Defect detection in selective laser melting technology by acoustic signals with deep belief networks," The International Journal of Advanced Manufacturing Technology, Volume 96, Issue 5-8, 2018, Pages 2791-2801.

32. A. Aldahash," Optimum manufacturing parameters in selective laser sintering of PA12 with white cement additives," The International Journal of Advanced Manufacturing Technology, Volume 96, Issue 1-4, 2018, Pages 257-270.

33. Kundakcıoğlu, I. Lazoglu, Ö. Poyraz, E.Yasa, N. Cizicioğlu," Thermal and molten pool model in selective laser melting process of Inconel 625," The International Journal of Advanced Manufacturing Technology, Volume 95, Issue 9-12, 2018, Pages 3977-3984.

34. Montonera, P. Nash," Sinter bonding titanium and Ti-6Al-4V," The International Journal of Advanced Manufacturing Technology, Volume 96, Issue 5-8, 2018, Pages 2907-2914.

35. Liu, J., Ma, Y., Qureshi, A.J. et al. Light-weight shape and topology optimization with hybrid deposition path planning for FDM parts. Int J Adv Manuf Technol 97, 1123-1135 (2018).

36. H. Cheng, R. Cui, H. Z. Wang, Z. T. Han," Effect of processing parameters of laser on microstructure and properties of cladding 42CrMo steel," The International Journal of Advanced Manufacturing Technology, Volume 96, Issue 5-8, 2018, Pages 1715-1724.

37. J. Liu, L. Fu, H. Y. Chen,"Effect of high rotational speed on temperature distribution, microstructure evolution, and mechanical properties of friction stir welded 6061-T6 thin plate joints," The International Journal of Advanced Manufacturing Technology, Volume 96, Issue 5-8, 2018, Pages 1823-1833.

38. Calleja, A., Bo, P., González, H. et al. Highly accurate 5-axis flank CNC machining with conical tools. Int J Adv Manuf Technol 97, 1605-1615 (2018).

39. Darshan, S. Jain, M. Dogra, M. K. Gupta, M. Mia \& R. Haque," Influence of dry and solid lubricantassisted MQL cooling conditions on the machinability of Inconel 718 alloy with textured tool," The International Journal of Advanced Manufacturing Technology, Volume 105, 2019, Pages 18351849.

40. Jia, C. Li, Y. Zhang, D. Zhang, X. Zhang," Experimental research on the influence of the jet parameters of minimum quantity lubrication on the lubricating property of Ni-based alloy grinding," The International Journal of Advanced Manufacturing Technology, 2016, Volume 82, Issue 1-4, Pages 617-630.

41. Wojtewicz, K. Nadolny, W. Kapłonek, K. Rokosz, D. Matýsek, M. Ungureanu," Experimental studies using minimum quantity cooling (MQC) with molybdenum disulfide and graphite-based microfluids 
in grinding of Inconel alloy 718," The International Journal of Advanced Manufacturing Technology, 2019, Volume 101, Issue 1-4, Pages 637-661.

42. M. A. Abdo, A. M. El-Tamimi, S. Anwar, U. Umer, A. M. Alahmari, M. A. Ghaleb," Experimental investigation and multi-objective optimization of Nd:YAG laser micro-channeling process of zirconia dental ceramic," The International Journal of Advanced Manufacturing Technology, 2018, Volume 98, Issue 5-8, Pages 2213-2230.

43. Yang, C. Li, Y. Zhang, D. Jia, R. Li, Y. Hou, H. Cao," Effect of friction coefficient on chip thickness models in ductile-regime grinding of zirconia ceramics," The International Journal of Advanced Manufacturing Technology, 2019, Volume 102, Issue 5-8, Pages 2617-2632.

44. Xu, Z. Yao, H. Cai, H. Wang," An experimental investigation of grinding force and energy in laser thermal shock-assisted grinding of zirconia ceramics," The International Journal of Advanced Manufacturing Technology, 2017, Volume 91, Issue 9-12, Pages 3299-3306.

45. W. Kim, C. M. Lee," A study on the development of milling process for silicon nitride using ball endmill tools by laser-assisted machining," The International Journal of Advanced Manufacturing Technology, 2015, Volume 77, Issue 5-8, Pages 1205-1211.

46. Azarhoushang, B. Soltani, A. Zahedi," Laser-assisted grinding of silicon nitride by picosecond laser," The International Journal of Advanced Manufacturing Technology, 2017, Volume 93, Issue 5-8, Pages 2517-2529.

47. Laouissi, M. A. Yallese, A. Belbah, S. Belhadi, A. Haddad," Investigation, modeling, and optimization of cutting parameters in turning of gray cast iron using coated and uncoated silicon nitride ceramic tools. Based on ANN, RSM, and GA optimization," The International Journal of Advanced Manufacturing Technology, 2019, Volume 101, Issue 1-4, Pages 523-548.

48. Fu, Y. Ma," A method to predict early-ejected plastic part air-cooling behavior towards quality mold design and less molding cycle time," Robotics and Computer-Integrated Manufacturing, Volume 56, 2019, Pages 66-74.

49. Kitayama, M.Yokoyama, M. Takano, S. Aiba," Multi-objective optimization of variable packing pressure profile and process parameters in plastic injection molding for minimizing warpage and cycle time," The International Journal of Advanced Manufacturing Technology, 2017, Volume 92, Issue 9-12, Pages 3991-3999.

50. Krebelj, M. Halilovič, N. Mole," The cooling rate dependence of the specific volume in amorphous plastic injection molding," The International Journal of Advanced Manufacturing Technology, 2019, Volume 103, Issue 1-4, Pages 1175-1184.

51. Li, Q. Lan, D. Dong, Z. Liu, Z. Li, Y. Bian," Integrated design and process analysis of a blow molding turbo-charged pipe," The International Journal of Advanced Manufacturing Technology, 2014, Volume 73, Issue 1-4, Pages 63-72.

52. Safarian, M.Subaşi, Ç. Karataş," The effect of sintering parameters on diffusion bonding of 316L stainless steel in inserted metal injection molding," The International Journal of Advanced Manufacturing Technology, 2017, Volume 89, Issue 5-8, Pages 2165-2173. 
53. Ramesh, M. Prabhakar, R. Narayanasamy," Workability studies on Al-5\%SiC powder metallurgy composite during cold upsetting," The International Journal of Advanced Manufacturing Technology, 2009, Volume 44, Issue 3-4, Pages 389-398.

54. I. Jeong, C. K. Jin, H. Y. Seo, J. D. Kim, C. G. Kang," Mold structure design and casting simulation of the high-pressure die casting for aluminum automotive clutch housing manufacturing," The International Journal of Advanced Manufacturing Technology, 2016, Volume 84, Issue 5-8, Pages 1561-1572.

55. Liu, L. Jie, Y. G. Wang," Entrance shape design of spread extrusion die for large-scale aluminum panel," The International Journal of Advanced Manufacturing Technology, 2019, Volume 101, Issue 5-8, Pages 1725-1740.

56. Hölker, M. Haase, N. B. Khalifa, A. E.Tekkaya," Hot Extrusion Dies with Conformal Cooling Channels Produced by Additive Manufacturing," Materials Today: Proceedings Volume 2, Issue 10, Part A, 2015, Pages 4838-4846.

57. R. Han, J. R. Cho, S. K. Beak, J. A. Hong, Y. S. Lee," Numerical and experimental studies of injection compression molding process for thick plastic gas valve stem," The International Journal of Advanced Manufacturing Technology, 2017, Volume 89, Issue 1-4, Pages 651-660.

58. Cortina , ID , J. I. Arrizubieta, A. Calleja, E. Ukar, A. Alberdi," Case Study to Illustrate the Potential of Conformal Cooling Channels for Hot Stamping Dies Manufactured Using Hybrid Process of Laser Metal Deposition (LMD) and Milling," Metals, 2018, Volume 8, Issue 102, Pages 1-15.

59. Zhou, W. Xue," Review of tool condition monitoring methods in milling processes," he International Journal of Advanced Manufacturing Technology," Volume 96, Issue 5-8, 2018, Pages 2509-2523.

60. Li, G. Wang, G. He," Surface quality monitoring based on time-frequency features of acoustic emission signals in end milling Inconel-718," The International Journal of Advanced Manufacturing Technology, Volume 96, Issue 5-8, 2018, Pages 2725-2733.

\section{Figures}




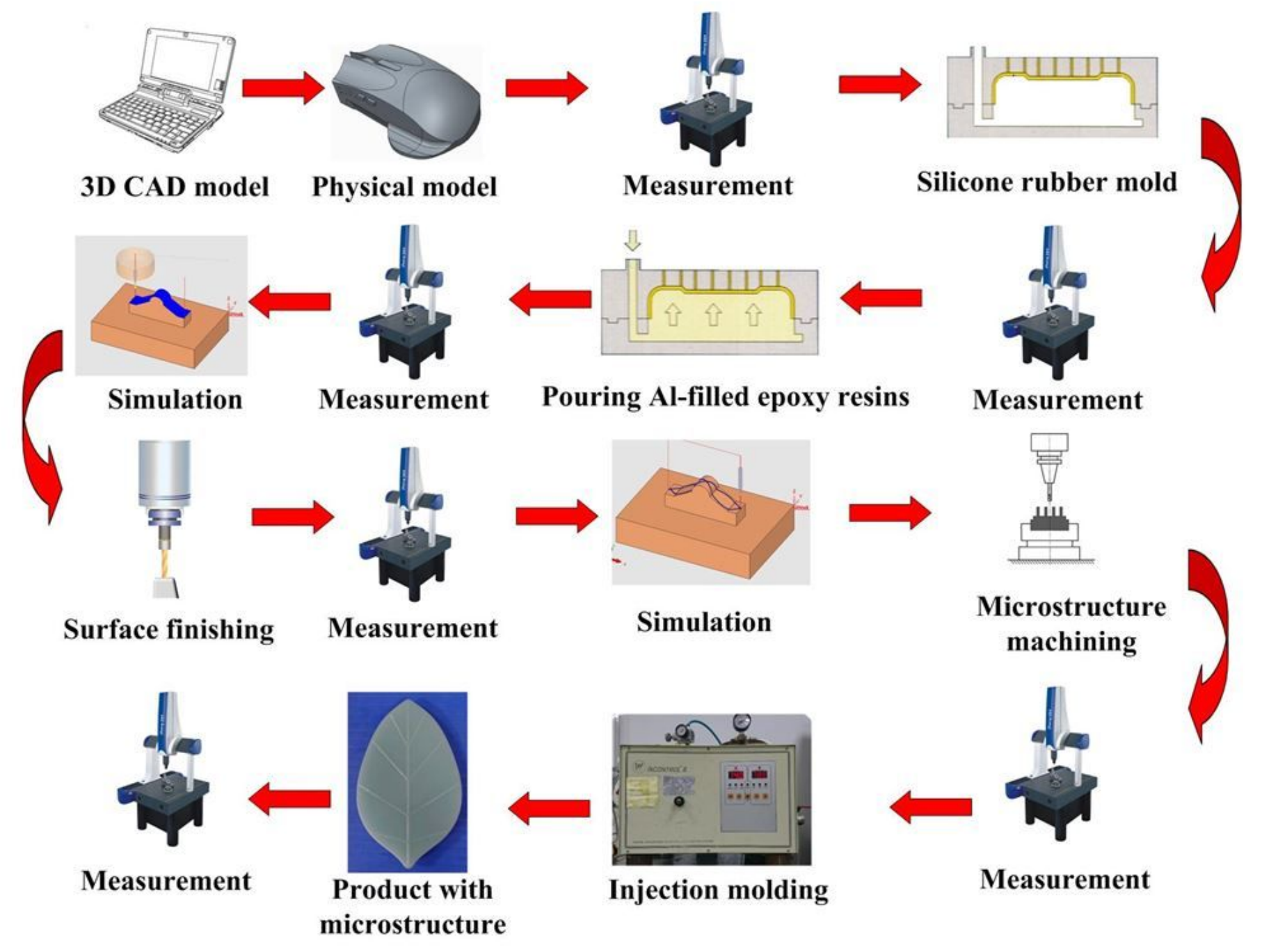

Figure 1

Steps of a cost-effective method for rapid manufacturing a precision part with microstructures using hybrid manufacturing technologies 


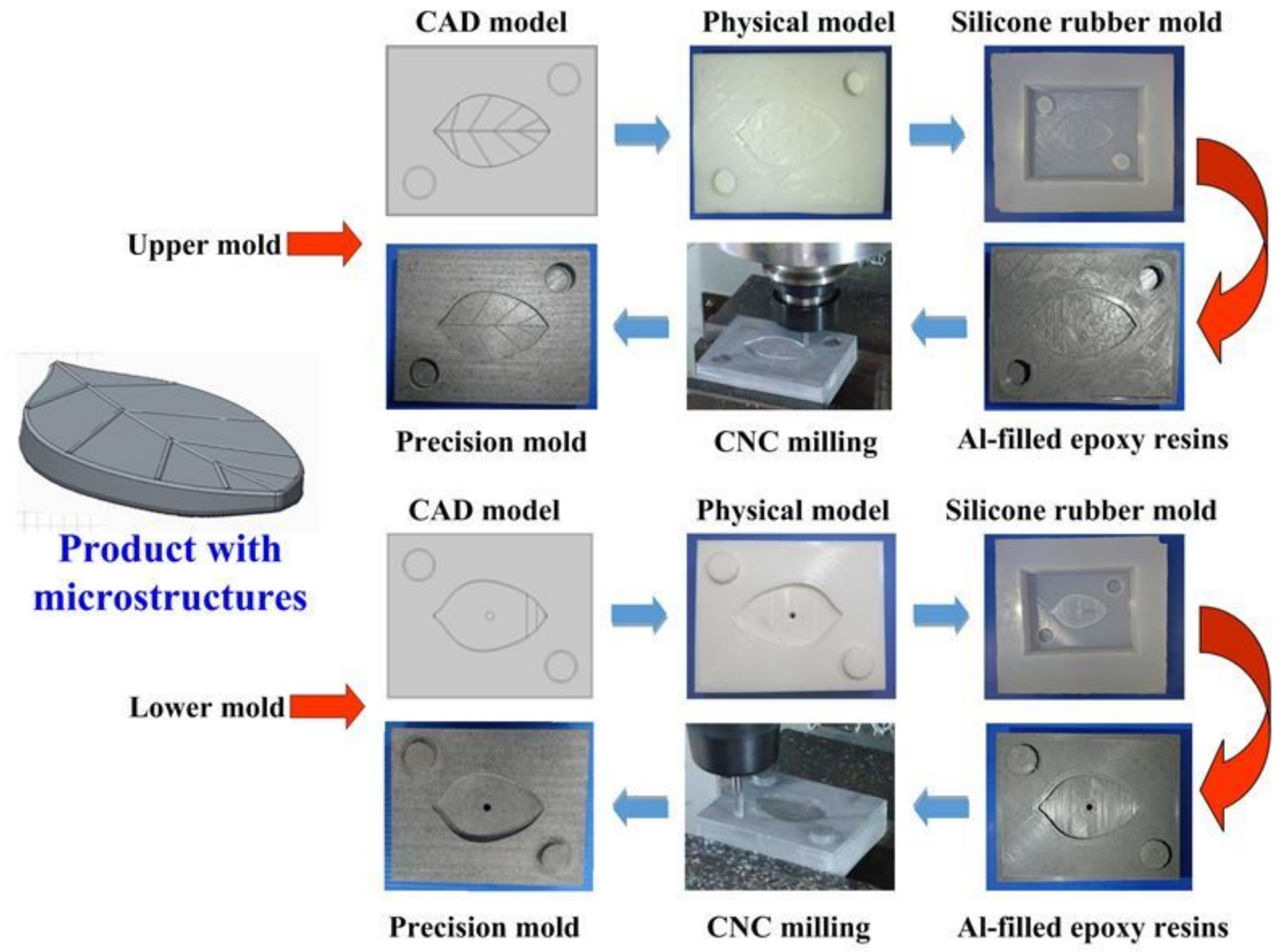

Figure 2

Steps of a cost-effective method for rapid manufacturing a precision mold for injection molding 


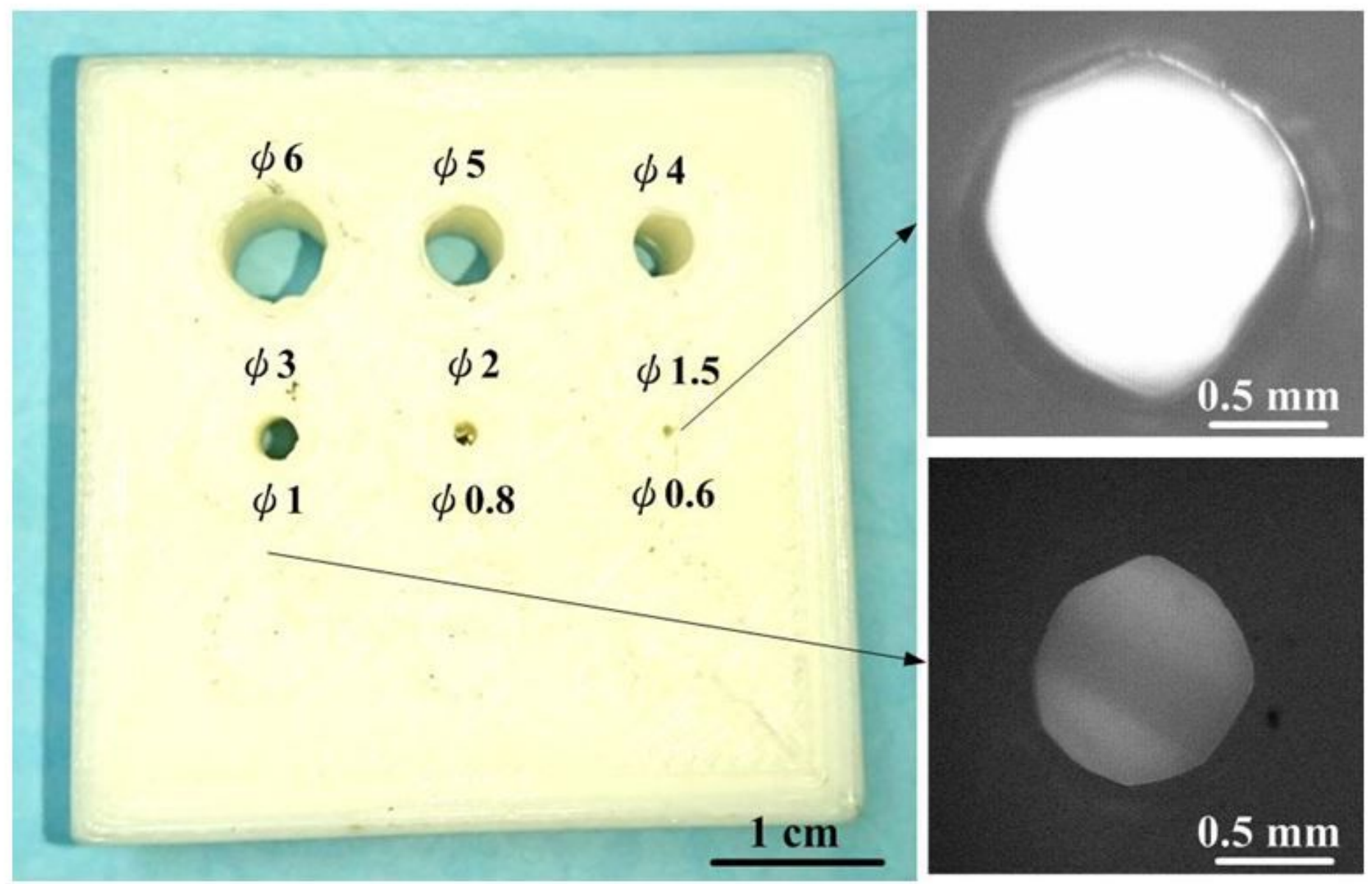

Figure 3

Different holes in the physical model fabricated by AM

Before

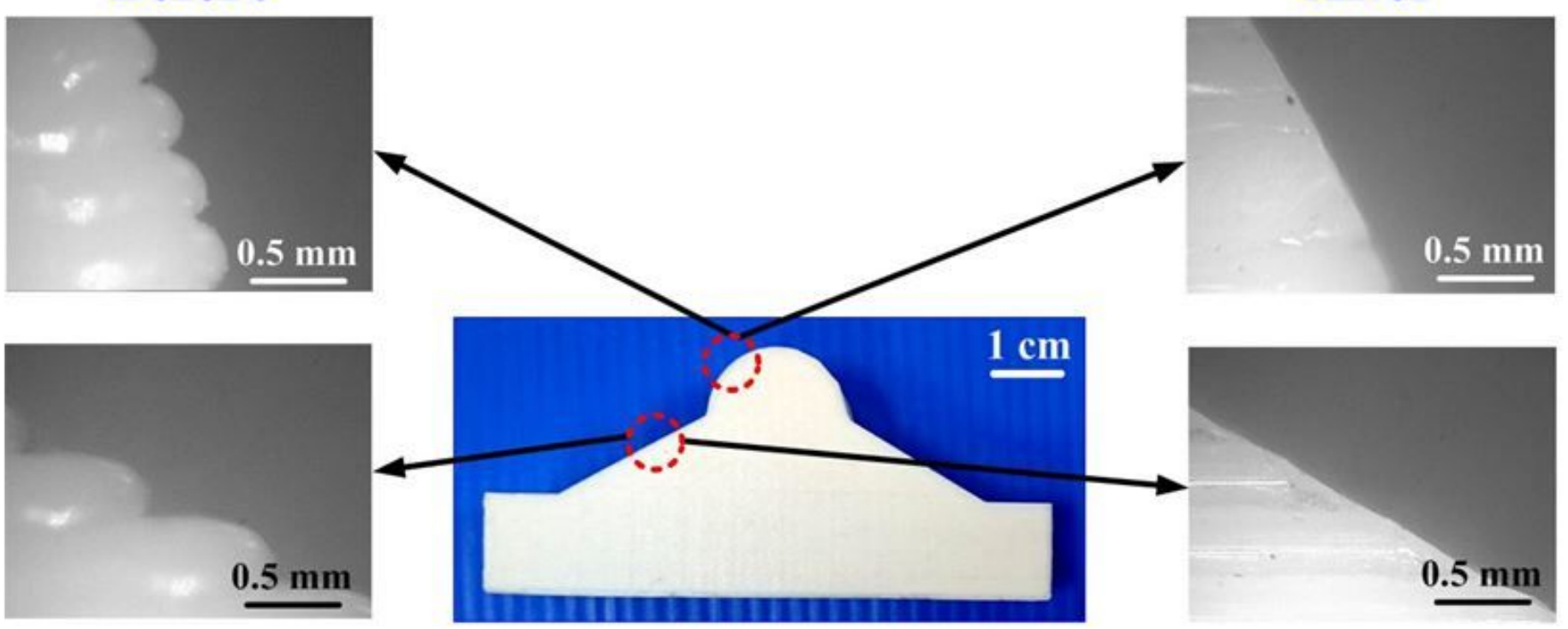

Figure 4 
Surface quality of a test part (a) before and (b) after CNC milling

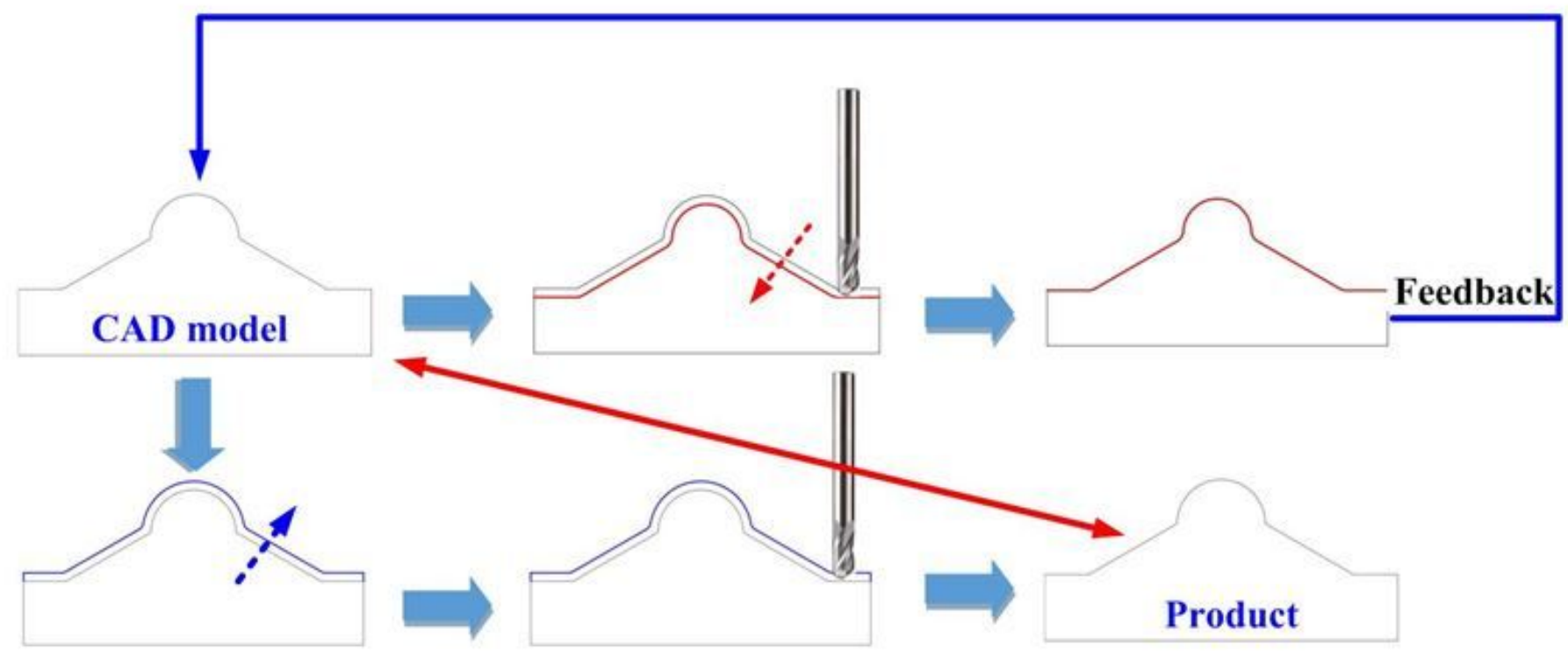

Figure 5

Process flows for maintaining both dimensional accuracy and surface quality of the part using CNC machining

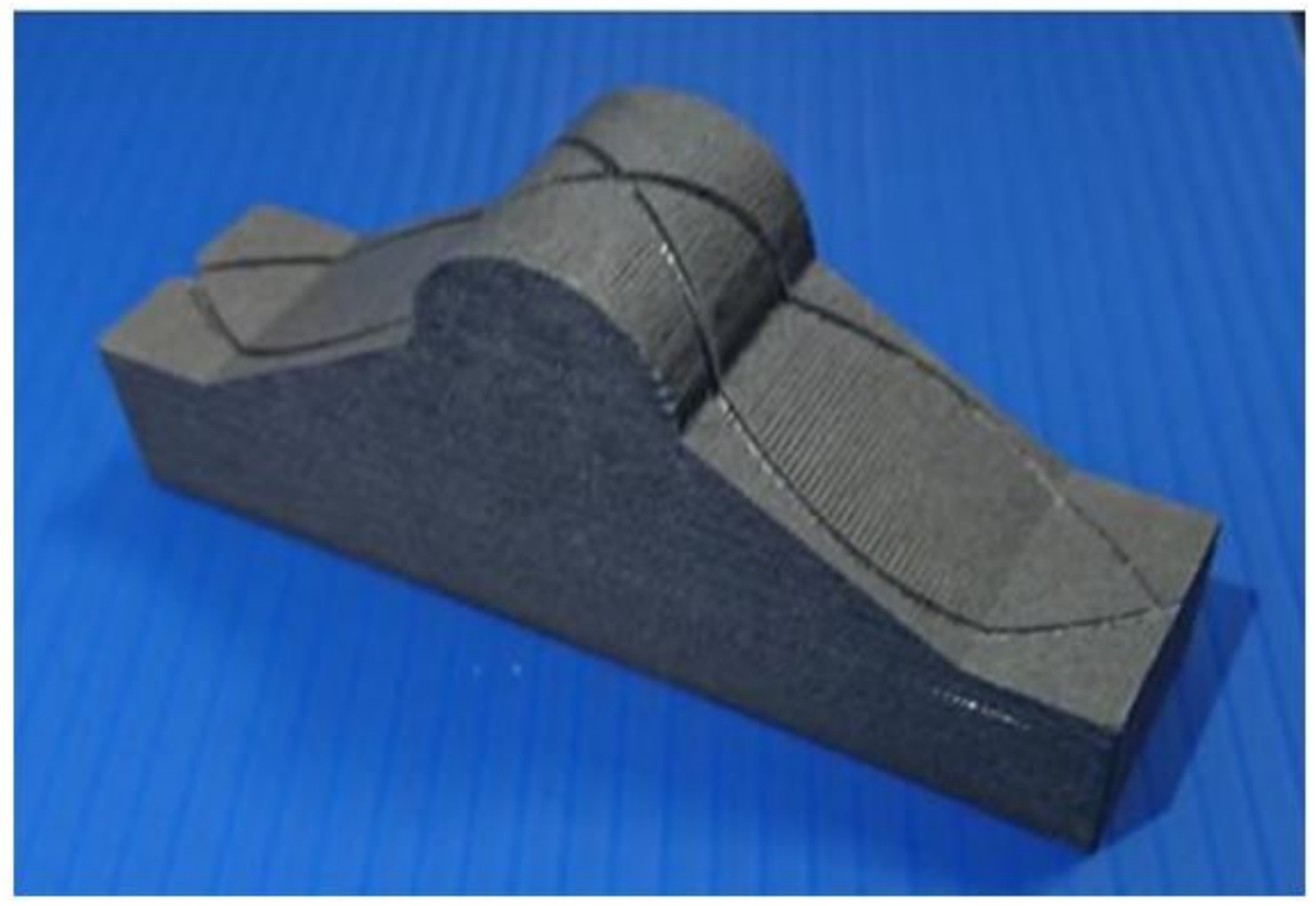

Figure 6 

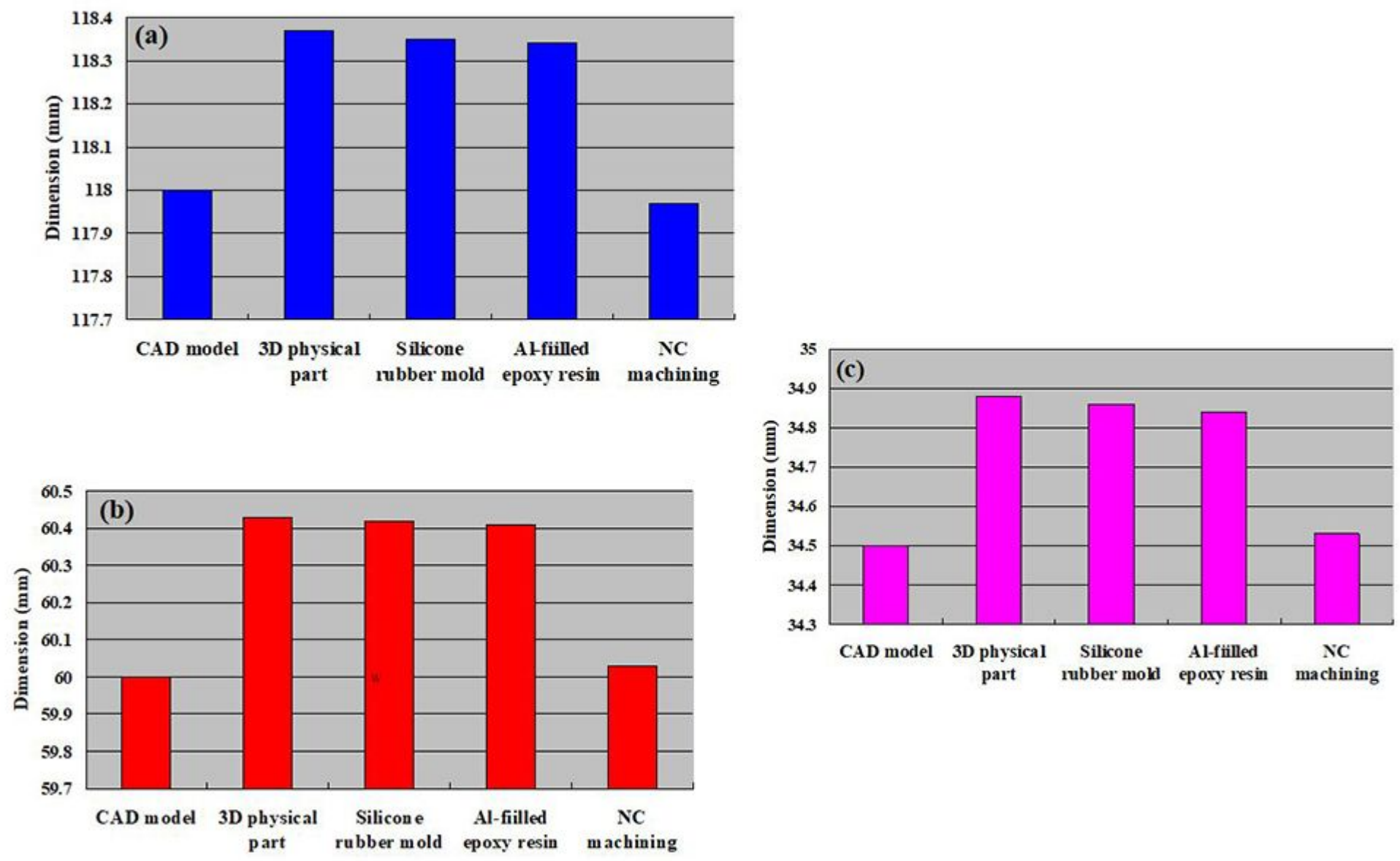

\section{Figure 7}

Variations in dimension of the precision component manufacturing process for (a) length, (b) width, and (c) height 


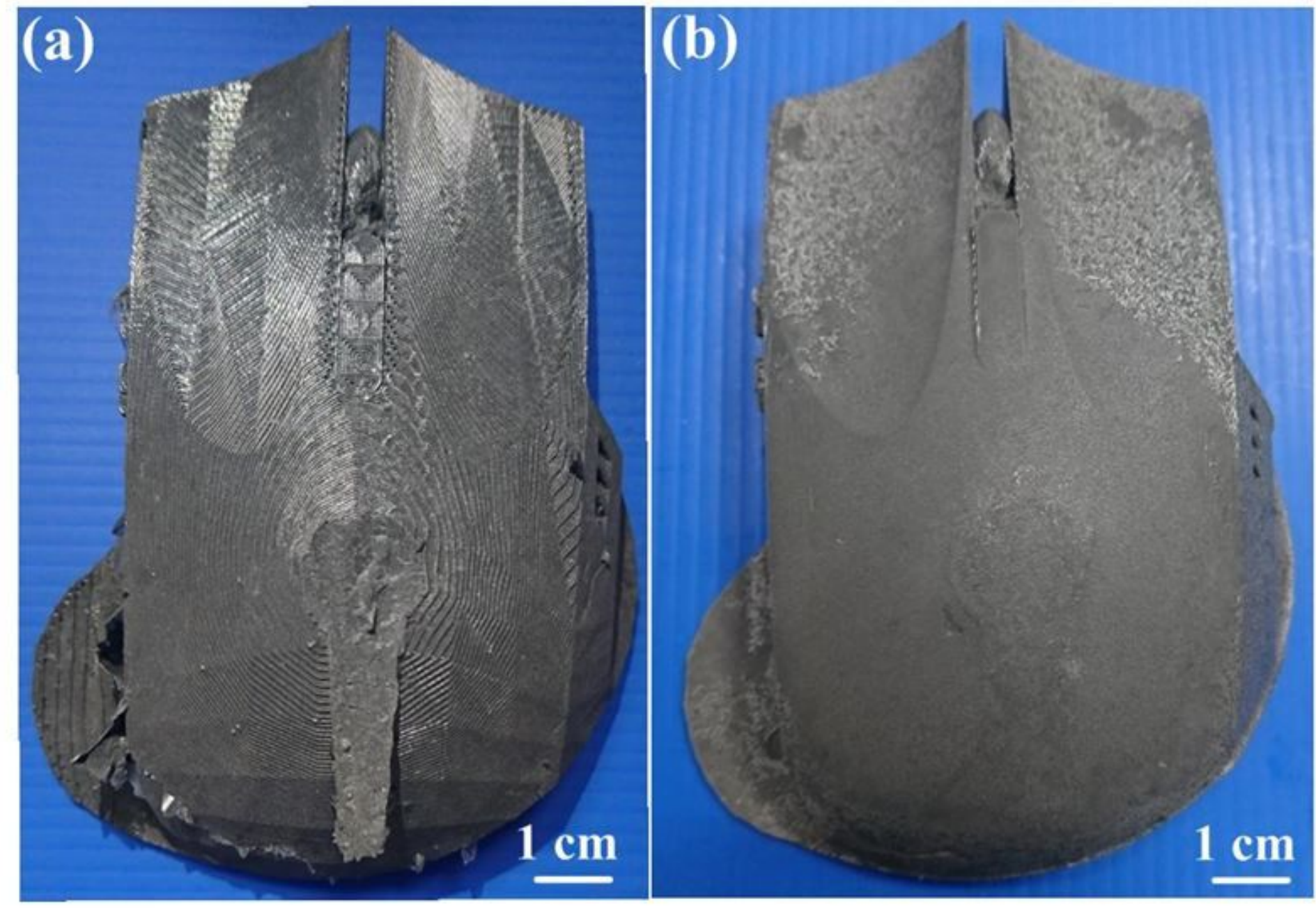

Figure 8

A precision component (a) before and (b) after CNC milling 

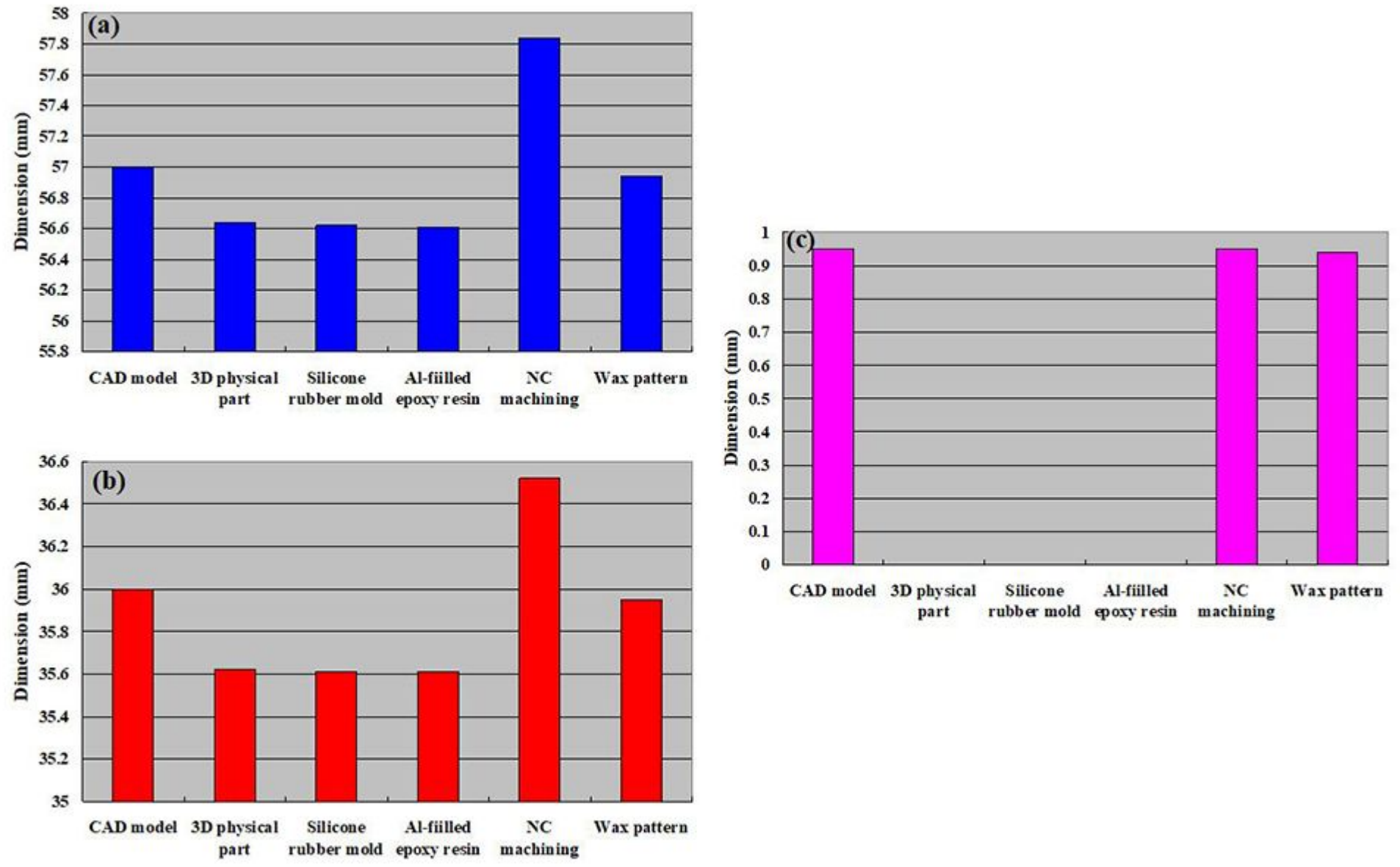

\section{Figure 9}

Variations in dimension of the precision mold manufacturing process for (a) length, (b) width, and (c) microstructures 


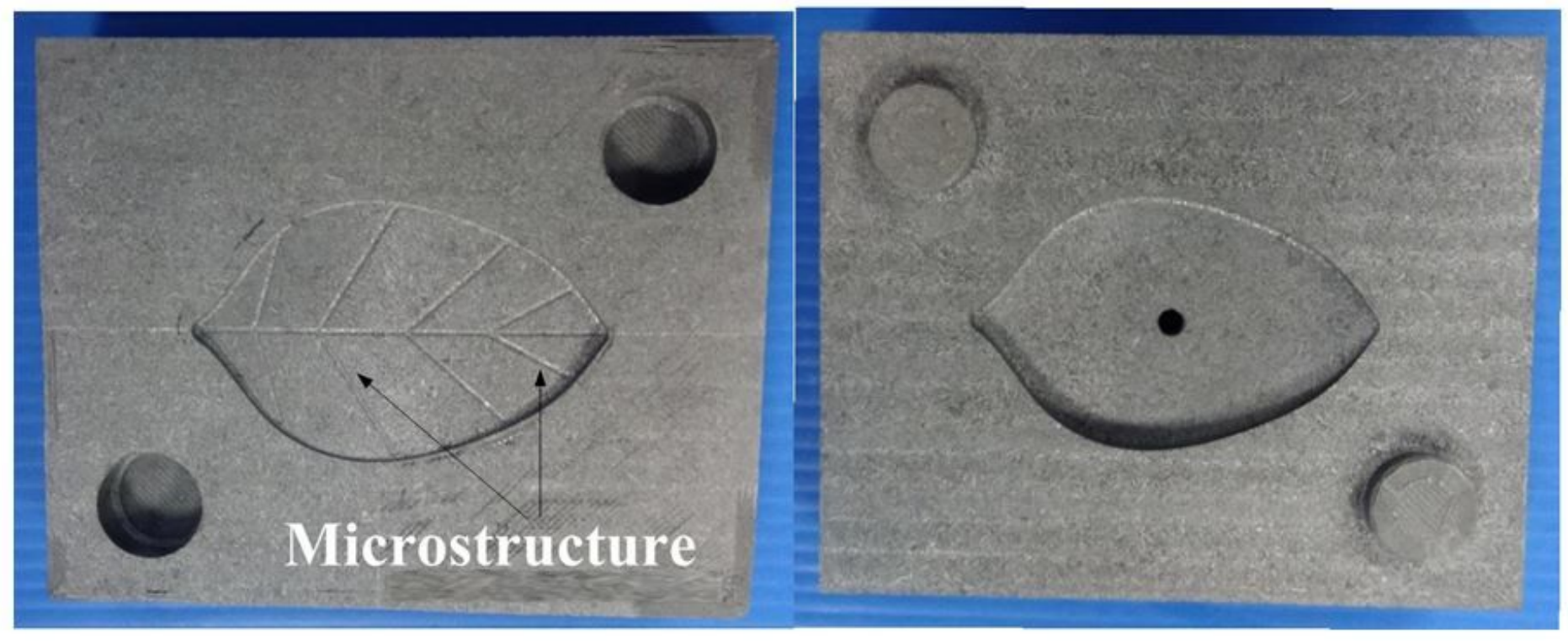

Figure 10

A precision injection mold with microstructure 


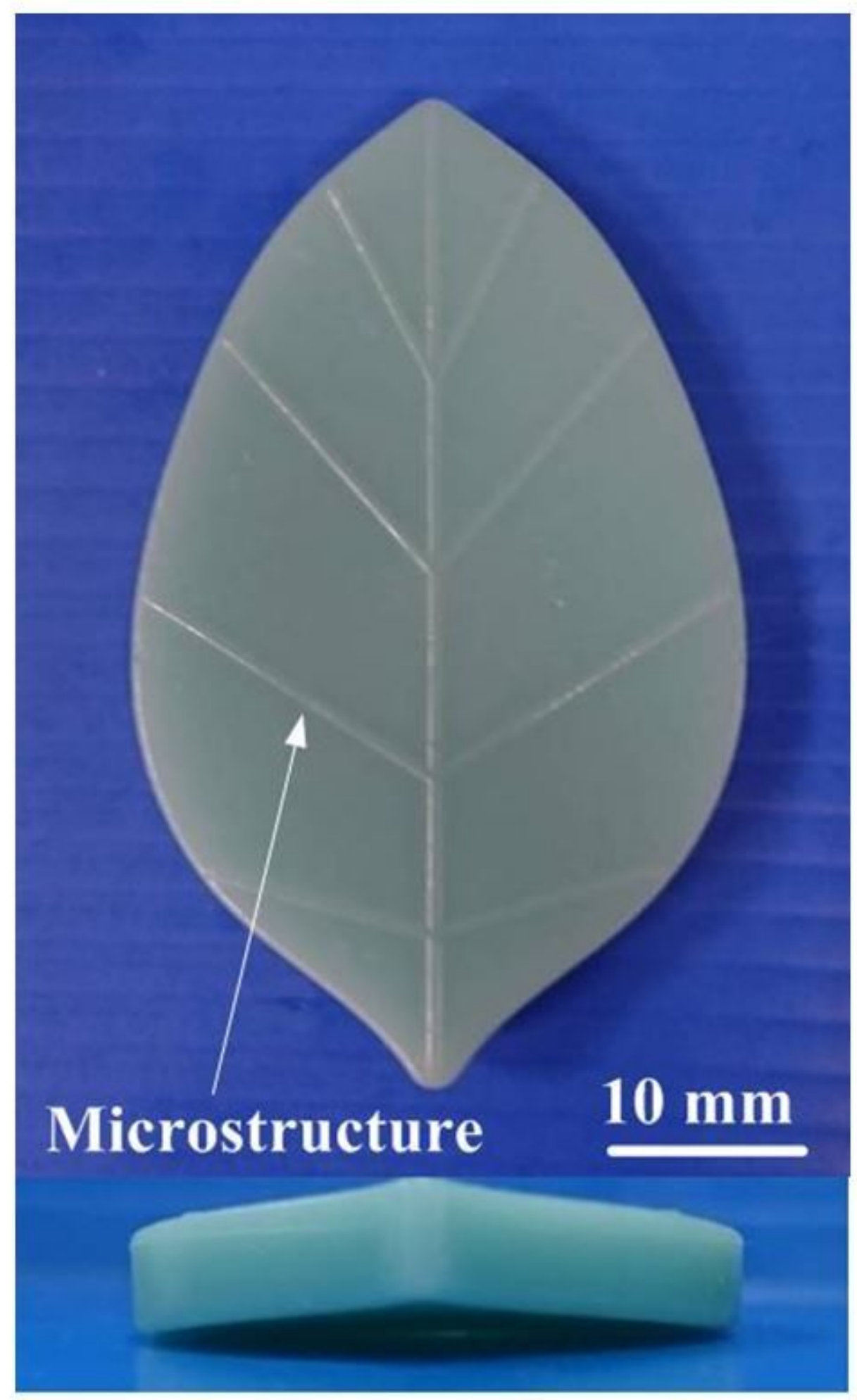

Figure 11

A wax pattern with microstructures fabricated by a precision injection mold through injection molding 


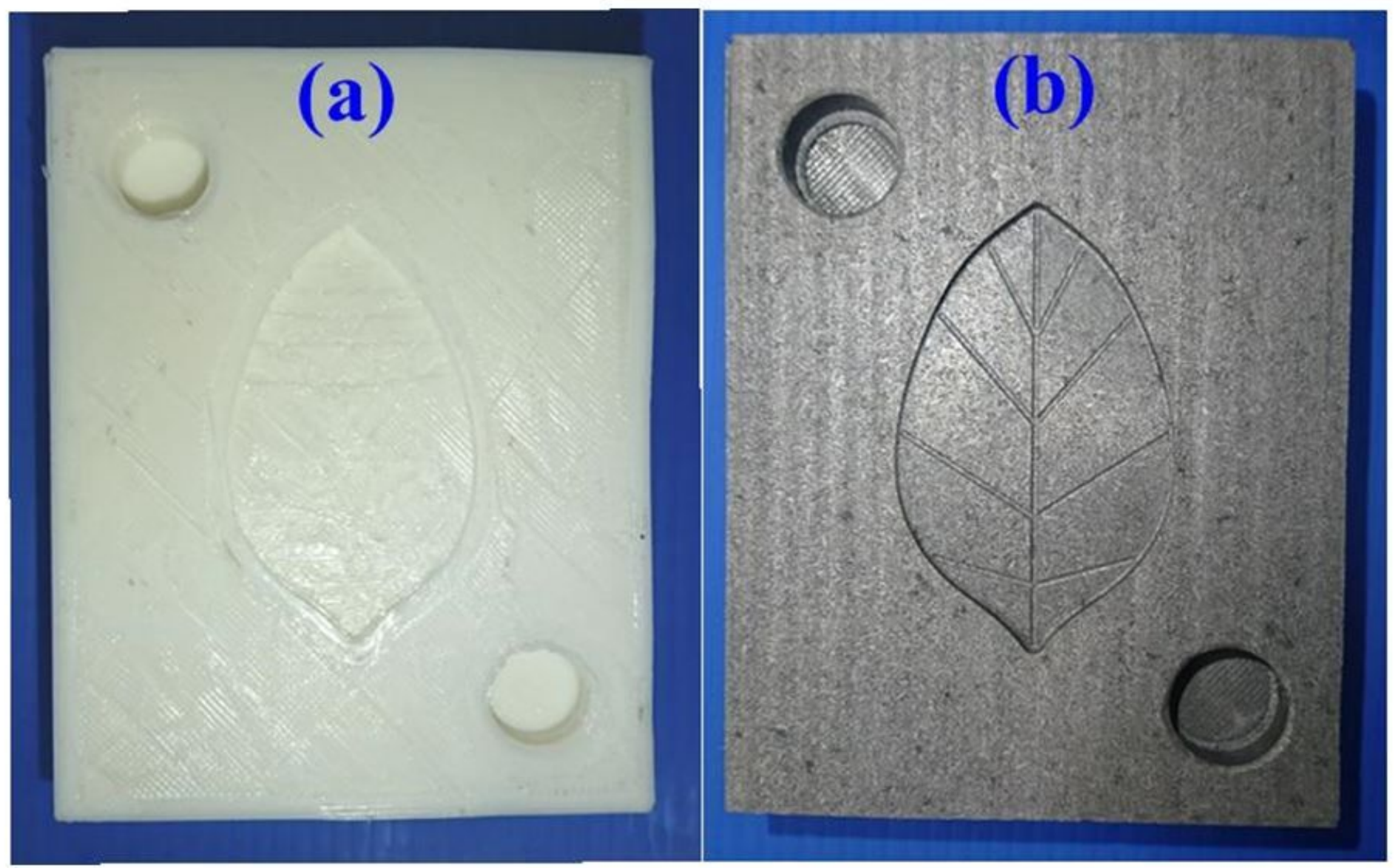

Figure 12

A precision injection mold fabricated by (a) AM technology and (b) hybrid manufacturing technology 